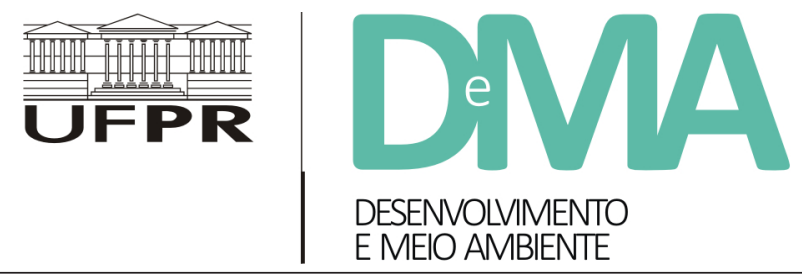

\title{
Percepção ambiental como subsídio para gestão costeira da Baía do Araçá, Litoral Norte do Estado de São Paulo, Brasil
}

\section{Environmental Perception as Support for Coastal Management in the Bay of Araçá, Northern Coast of the São Paulo State, Brazil}

\author{
Natalia Ruiz de OLIVEIRA ${ }^{1}$, Claudia Regina dos SANTOS $^{1 *}$, Alexander TURRA ${ }^{1}$ \\ ${ }^{1}$ Instituto Oceanográfico (IO), Universidade de São Paulo (USP), São Paulo, SP, Brasil. \\ *E-mail de contato: biolsantos@hotmail.com
}

Artigo recebido em 10 de julho de 2017, versão final aceita em 26 de novembro de 2017.

RESUMO: As Zonas Costeiras são responsáveis por uma ampla gama de funções ecológicas, mas também são objetos de preocupação por sua integridade e equilíbrio ambiental devido aos seus diferentes usos e às pressões sofridas. Tal cenário soma-se à não inclusão da percepção ambiental da população como estratégia de gestão e como modo de ampliar a participação da sociedade nesse processo, entendendo-se que, por sua vez, esta percepção pode ser influenciada pela classe etária e pelo tipo de relacionamento que as pessoas mantêm com o local. Este estudo objetiva avaliar diferenças nas percepções do ambiente marinho de indivíduos de classes etárias variadas ( 07 a 16 anos; 17 a 34 anos; 35 a 50 anos e maiores que 50 anos), considerando os indicadores: importância do local, senso de pertencimento, senso de responsabilidade e interesse, na região da Baía do Araçá, São Sebastião, São Paulo, Brasil. Com relação à importância do Araçá, os indivíduos mais jovens mostram-se ligados preferencialmente ao lazer que a baía proporciona e à pesca familiar. Já para os mais velhos, a pesca é tema de maior importância. Quanto ao senso de pertencimento, há uma diferença que depende parcialmente da classe etária, mas a maioria dos indivíduos entrevistados revela gostar de morar ali e usa a baía de diferentes formas. Os menores sensos de responsabilidades foram observados nos indivíduos de 17 a 34 anos, ao contrário da classe etária mais jovem. O distanciamento em relação à Baía do Araçá foi geralmente observado em indivíduos que não utilizam a baía de nenhuma forma ou não a conhecem muito bem, apesar de morarem ali desde o nascimento, independente da classe etária. Assim, constata-se que a percepção e o envolvimento com o local estão mais relacionados com o conhecimento, o uso e a criação de uma identidade com a região do que com a idade.

Palavras-chave: percepção ambiental; serviços ecossistêmicos; Baía do Araçá; gestão costeira; ecologia humana. 
ABSTRACT: Coastal zones are responsible for a wide range of ecological functions but are also objects of concern for their integrity and environmental balance due to their different uses and pressures suffered. Such scenario adds up to the non-inclusion of the environmental perception of the population as a management strategy and as a way to broaden the participation of society in this process, understanding that, in turn, this perception can be influenced by the age group and the type of relationships that people keep with the place. The aim of this study was to evaluate differences in marine environmental perceptions according to different age groups (from 07 to 16 years, from 17 to 34 years, from 35 to 50 years and older than 50 years) considering as indicators: importance, sense of belonging, sense of responsibility and interest, in the Araçá Bay, São Sebastião, São Paulo, Brazil. Regarding the importance of Araçá, younger interviewees are shown to be linked preferably to the leisure and family fishing that the bay provides. As for the older, fishing is a matter of major importance. Concerning the sense of belonging, there is a difference that partially depends on the age group, but most of the individuals interviewed like to live there and use the Bay in different ways. The lowest sense of responsibility was observed in individuals aged 17 to 34 years, as opposed to the younger age group. The lower involvement with Araçá Bay was observed in the interviewees who do not use the bay in any way or do not know it very well, despite living there since birth, regardless to the age group. Thus, it is verified that the involvement of people with this site is much more related to the knowledge, the use and creation of an identity with the region than with the age.

Keywords: environmental perception; ecosystem services; Araçá Bay; coastal management; human ecology.

\section{Introdução}

A preocupação com a integridade e com o equilíbrio ambiental da Zona Costeira decorre do fato de ela figurar entre as regiões mais ameaçadas do planeta, justamente por representar para as sociedades humanas um espaço de alto valor, servindo como local de lazer, de turismo ou de moradia de grandes populações urbanas e sendo alvo da exploração desordenada e predatória (Halpern et al., 2008; 2012). Junto com o uso do espaço, a gestão de recursos naturais é um grande desafio da atualidade, havendo necessidade de ações corretivas e preventivas na mediação de "múltiplos conflitos de uso" dos espaços e dos recursos naturais (ANA, 2012). A Gestão Costeira Integrada (GCI) encaixa-se nessa necessidade, definindo-se como um processo contínuo e dinâmico pelo qual são tomadas decisões para o uso sustentável, o desenvolvimento e a proteção das zonas e recursos costeiros e marinhos (Cicin-Sain \& Knecht, 1998). Trata-se de um processo que une governo e comunidade, ciência e gestão, interesses privados e públicos na preparação e na implementação de um plano integrado para a proteção e o desenvolvimento dos ecossistemas e recursos costeiros (GESAMP, 1996). Nesse cenário, entretanto, a participação da sociedade civil ainda é muito limitada (Jacobi \& Barbi, 2007; Peterson, 2011), o que pode comprometer o controle social. Estudos mostram que a participação social está intimamente relacionada com o acesso à informação e com as diferentes visões de mundo dos atores sociais (Ehler, 2003; Dagnino, 2004; Gohn, 2006). Há indícios de que a idade está negativamente correlacionada com a preocupação ambiental, ou seja, que os mais jovens tendem a se preocupar mais com o meio ambiente comparativamente aos indivíduos mais velhos (Van Liere \& Dunlap, 1980). Porém, o inverso (Shen \& Saijo, 2008; Villar et al., 2008) ou mesmo a indiferença em relação à idade (Trenouth et al., 2012) também foram registrados. Alguns estudos de percepção ambiental, por exemplo, 
evidenciam a diferença de interesses entre classes etárias, observando a tendência de rejeição dos mais jovens por seguir o modo de vida dos pais, principalmente quando se trata da juventude rural, onde predomina a imagem de um jovem desinteressado pelo meio natural e atraído pela cidade (Champagne, 1986; Ferrante \& Aly Junior, 2005). Isso poderia desencadear um processo de distanciamento dos jovens em relação à temática local e ambiental, comprometendo a participação e o controle social no médio e longo prazos.

Uma forma de incentivar e ampliar a participação da sociedade civil nos processos de GCI é a utilização da percepção ambiental como ferramenta de diagnóstico e estratégia de planejamento do uso dos espaços e dos recursos. Apesar de não estarem expressas em instrumentos formais, como leis e instituições, as percepções, as aspirações e as visões de mundo também influenciam diretamente o manejo dos recursos naturais e deveriam ser explicitamente levadas em consideração pelos órgãos envolvidos (Whyte, 1977; GESAMP, 1996). Neste contexto, a percepção ambiental se mostra uma importante ferramenta para a GCI (Turner, 2000; Ehler, 2003; Fernandes et al., 2003; Delmas \& Toffel, 2004; Xavier, 2010; Martinez, 2012; Shirazawa-Freitas, 2012). A percepção ambiental pode ser definida como a forma individual de ver, compreender e se comunicar com o ambiente, levando em conta as influências ideológicas de cada sociedade, como valores e normas (UNESCO, 1973), e as características de cada indivíduo, como gênero, idade, classe social, renda, educação, erudição, local de moradia, preferências e individualidades (Oliveira \& Corona, 2008; Knopki et al., 2008; Villar et al., 2008; Trenouth et al., 2012).
A percepção dos diferentes atores sociais sobre o meio ambiente local pode identificar as necessidades, os valores, as ameaças e as fortalezas da comunidade e do ambiente; possibilitar o uso do conhecimento tradicional e seus contrastes com visão da comunidade científica e dos órgãos gestores; ajudar na preservação do conhecimento e dos saberes que estão sendo rapidamente perdidos nas comunidades tradicionais; indicar o grau de comprometimento das pessoas com determinada região ou questão ambiental e, assim, determinar o engajamento e a participação da sociedade em discussões sobre seu futuro (Whyte, 1977; Martinez, 2012; Trenouth et al., 2012; Abecasis et al., 2013; Benitez-Capistros et al., 2014). A percepção ambiental também vem sendo utilizada como instrumento de pré-diagnóstico de comunidades a que se pretende propor programas de Educação Ambiental, evitando, como muitas vezes ocorre, oferecer um programa sem aderência com as expectativas dos participantes. A percepção auxilia no direcionamento das atividades às reais necessidades e vulnerabilidades da comunidade, identificadas nos segmentos entrevistados (Fernandes et al., 2003; Bergmann, 2007; Oliveira \& Corona, 2008; Malafaia \& Rodrigues, 2009). Além disso, a pesquisa sobre percepção ambiental pode agir como uma ferramenta educacional e um agente de mudança para os envolvidos na pesquisa, pois desperta uma maior responsabilidade e o respeito dos indivíduos em relação ao ambiente em que vivem (Whyte, 1977; Marques \& Colesanti, 2001).

Emerge nesse contexto a discussão dos "referenciais mutáveis" (do inglês, shifting baselines; Campbell et al., 2009) e suas potenciais consequências para a cogestão de recursos naturais. Trata-se de um fenômeno social (Pauly, 1995) ou amnésia geracional (Kahn \& Friedman, 1995; Papworth et al., 
2009), presente dentro das comunidades, utilizado para referir-se ao fenômeno de mudança ecológica primária das condições ambientais, como a perda de biodiversidade (Turvey et al., 2010), a eutrofização (Duarte et al., 2009), o declínio dos recursos pesqueiros (Baum \& Myers, 2004), as comunidades tradicionais de florestas tropicais (Pauly, 1995) e a conservação marinha (Canright, 2006; Knowlton \& Jackson, 2008; Papworth et al., 2009), que são percebidos de forma diferente por indivíduos que viveram em conjunturas ou momentos diferentes.

Neste contexto, esta pesquisa objetiva avaliar as diferenças de percepções do ambiente marinho por indivíduos de diferentes classes etárias, considerando: a) a importância atribuída ao local; b) o senso de pertencimento em relação ao local; c) o senso de responsabilidade em relação ao local; e d) o interesse por questões relacionadas ao local. Esses aspectos refletem a percepção ambiental que o indivíduo possui do ambiente, demonstrando a maneira como ele vê, compreende e se comunica com o meio. Espera-se averiguar se está havendo um distanciamento (no sentido de "menor envolvimento") dos mais jovens quanto a uma dada região em comparação aos indivíduos mais velhos. Como estratégia analítica, será utilizada a situação vivenciada por comunidades tradicionais caiçaras na região costeira do Estado de São Paulo, Brasil, na qual há registros de distanciamento dos jovens tanto da pesca quanto da própria região em função da busca por alternativas de trabalho e renda e da própria perda de qualidade ambiental da zona costeira (Leite, 2001).

\section{Métodos}

\section{1. Área de Estudo}

A Baía do Araçá localiza-se no município de São Sebastião, no Litoral Norte do Estado de São Paulo, Brasil, e constitui-se em um dos últimos relictos das áreas de manguezal no trecho entre Bertioga e Ubatuba (Figura 1). A baía é uma área de grande complexidade ambiental e alta diversidade biológica (Amaral et al., 2010; 2015). Faz parte da Área de Proteção Ambiental Marinha do Litoral Norte de São Paulo e da Área de Proteção Ambiental Marinha Municipal de Alcatrazes e há muitos anos está exposta a variados tipos de ação antrópica e de diferentes magnitudes, como: ocupações irregulares, turismo sazonal, lançamento de resíduos sólidos e efluentes de esgoto doméstico e proximidade do Porto de São Sebastião e do Terminal Aquaviário da Petrobrás, onde ocorrem recorrentes vazamentos de óleo, além de outras perturbações (Amaral et al., 2010; Turra et al., 2016).

A região abrange ainda a área de possível expansão do Porto de São Sebastião, condição em que se encontram diversas outras áreas costeiras ao longo do mundo, devido aos gargalos logísticos e à necessidade de expansão portuária. A presente situação de impacto sugere uma carência de medidas de gestão ambiental apropriadas para a área (Turra et al., 2016). Neste cenário, com vistas à gestão integrada, torna-se relevante a identificação da importância da baía por quem vive próximo a ela.

Como esse estudo objetiva fazer comparações entre diferentes classes etárias, torna-se necessário controlar outros parâmetros, como a localidade mais próxima geograficamente da baía. Assim, escolheu-se a área contígua, adjacente à baía, denominada Bairro Varadouro, que tem uma estimativa 
populacional de 400 habitantes, como modelo para essa abordagem de estudo. Como essa localidade ainda possui representantes da comunidade caiçara que ocupava tradicionalmente a região, há a oportunidade de avaliar a relação de pessoas com um referencial antigo do local e verificar se está havendo uma mudança de percepção e de relação com a área, com afastamento dos filhos e netos de pescadores das atividades tradicionalmente realizadas por eles (Campbell et al., 2009). Desse modo, é possível identificar e analisar a visão desses jovens, que podem possuir, hipoteticamente, uma relação diferenciada com a região.

\subsection{Entrevistas}

Para estudos no âmbito da percepção ambiental, é essencial que se adote uma ferramenta metodológica que seja participativa e permita que os sujeitos e grupos analisados, com suas experiências, exerçam a maior influência sobre os resultados (Martinez, 2012).

Tomando como base o trabalho de Knopki et al. (2008), que fizeram análise de percepção ambiental utilizando indicadores de contato, importância e participação, para essa pesquisa foram criados os indicadores de importância, pertencimento,

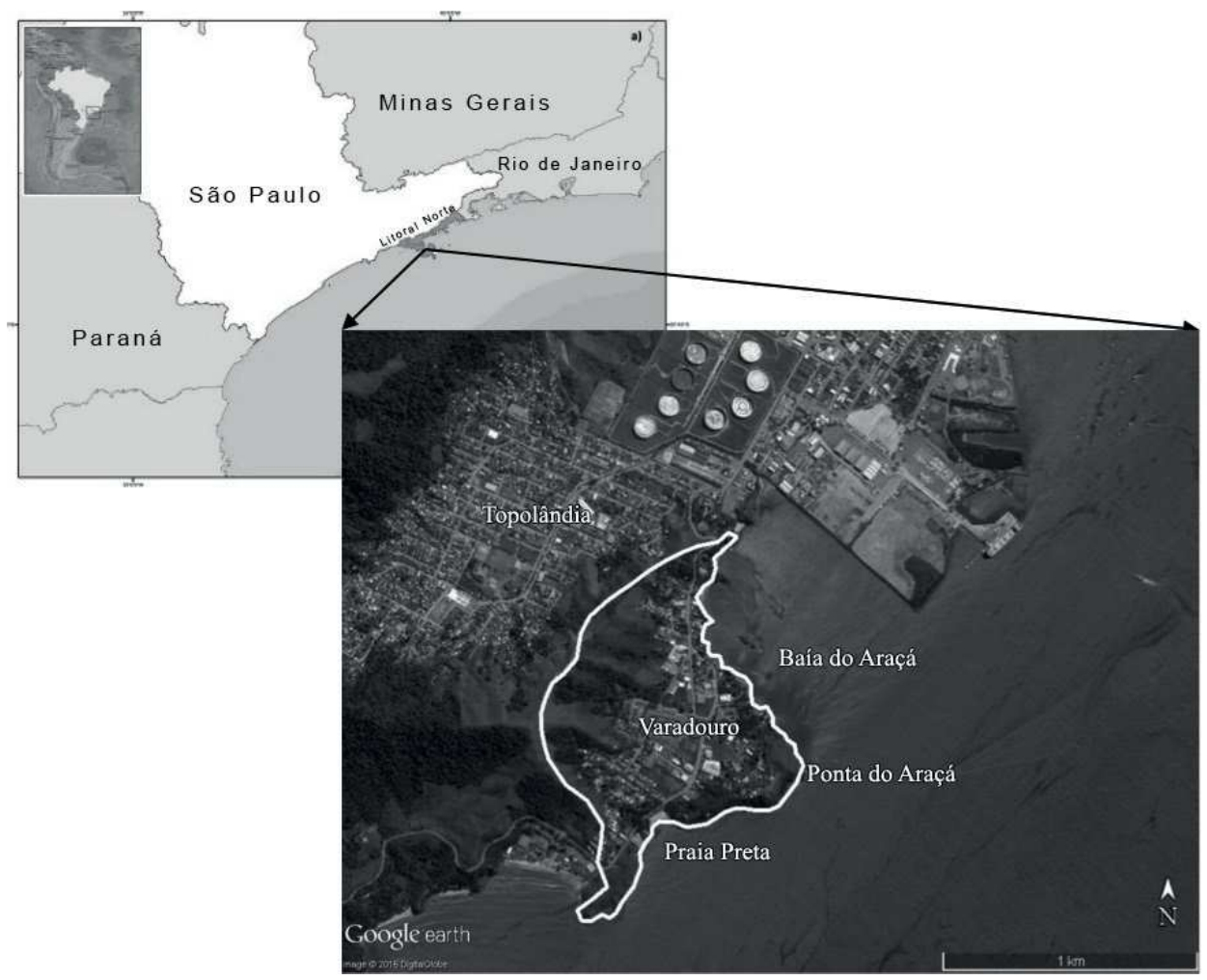

FIGURA 1 - Localização da Baía do Araçá e o bairro Varadouro em destaque, São Sebastião, SP. FONTE: Adaptado de Google Maps. 
responsabilidade e interesse. Foram então realizadas entrevistas semiestruturadas que permitem ao respondente discorrer sobre o tema proposto (Boni \& Quaresma 2005).

As entrevistas foram realizadas de acordo com as diretrizes de Bourdieu (1999), procurando falar a mesma língua do entrevistado, ou seja, tentar diminuir as diferenças culturais entre o pesquisador e o pesquisado; estar sempre atento ao entrevistado, enviando sinais de entendimento e estímulo; proporcionar bem-estar ao pesquisado; ter familiaridade com os temas abordados na entrevista e tentar se colocar no lugar do outro para melhor compreensão.

A fim de guiar a conversa entre pesquisador e moradores, foi elaborado um roteiro com questões separadas em blocos temáticos (orientadores para o próprio pesquisador) (Oliveira, 2013), de forma a otimizar o tempo e atingir os objetivos do trabalho (Bartolomé, 1997). Ressalta-se que, para identificar se os entrevistados reconhecem a importância da baía, mesmo não usando a área, foram realizadas perguntas de forma genérica (A baía é importante? Por quê?) e de forma pessoal (A baía é importante pra você? Por quê?).

As entrevistas foram realizadas entre os meses de julho e setembro de 2013, direcionadas a indivíduos nascidos em São Sebastião e moradores do bairro Varadouro desde o nascimento, selecionados segundo as classes etárias: (1) de 07 a 16 anos, (2) de 17 a 34 anos, (3) de 35 a 50 anos e (4) maiores que 50 anos. Tais classes foram escolhidas com base em Villar et al. (2008).

Para cada uma das classes etárias, foram feitas 10 entrevistas, totalizando 40 . O número de entrevistas foi delimitado levando em consideração essa ser uma pesquisa de perspectiva da percepção ambiental na região e que possui uma abordagem qualitativa, buscando fazer análise do discurso dos entrevistados.

A estratégia de amostragem utilizada foi o método snowball, descrito por Wright \& Stein (2005). A identificação de pessoas com as características citadas acima iniciou-se após uma visita prévia à região e seguiu, posteriormente, o método conhecido como "bola de neve" ou snowball sampling, no qual as primeiras pessoas interrogadas indicam outras que se encaixam no perfil da pesquisa.

Apenas no caso da classe etária de 07 a 16 anos, por facilidade, resolveu-se buscar esses indivíduos nas escolas da região. Foram escolhidas duas escolas estaduais de São Sebastião que, segundo os moradores, são as mais frequentadas pelos jovens moradores do bairro Varadouro (no próprio bairro não há escolas ou creches). Em cada escola visitada havia cinco estudantes que moravam no Varadouro desde o nascimento e, então, estes foram entrevistados, com supervisão da direção das escolas.

Com o consentimento dos participantes ou de seus responsáveis, as entrevistas foram gravadas e posteriormente transcritas e analisadas de forma qualitativa, utilizando-se a técnica de análise do discurso (Fiorin, 2000; Capelle et al., 2003). Buscou-se identificar elementos no discurso dos entrevistados que permitissem a interpretação dos indicadores propostos (importância, pertencimento, responsabilidade e interesse), apropriando-se de uma abordagem dialética para a comparação das percepções entre classes etárias.

Para análise de respostas discursivas, foi feito o agrupamento em diferentes categorias. Assim, uma única entrevista pôde ser incluída em diferentes categorias. Esses resultados foram representados por meio de porcentagens (porcentagem de respostas abordando uma categoria, por classe etária). 
Dessa maneira, foi sistematizado quantas vezes determinada informação aparecia em cada classe etária, aumentando assim o número amostral (número de respostas e não de entrevistados) e permitindo a apresentação dos resultados em porcentagens.

\section{Resultados}

As características básicas dos entrevistados variaram entre as classes etárias analisadas. Todos os entrevistados da menor classe etária são estudantes, sendo a maioria do sexo masculino e com uma média de idade igual a 13,7 anos. Na classe etária de 17 a 34 anos, havia seis estudantes, duas donas de casa, um pescador e um funcionário público, com média de idade igual a 23 anos. Os indivíduos com idade entre 35 e 50 anos foram em sua maioria do sexo feminino, apresentaram uma média etária de 45,4 anos e possuíam profissões diversas, como dona de casa $(\mathrm{n}=3)$, pescador $(\mathrm{n}=3)$, professor, diarista, sociólogo, pedreiro e guarda portuário. A classe de maior idade apresentou uma média de idade de 60,5 anos, predominância do sexo masculino e profissões como pescador $(\mathrm{n}=4)$, dona de casa $(\mathrm{n}=2)$, vigilante, porteiro, fotógrafo, marinheiro e artesão de canoas.

\subsection{Importância atribuída à Baía do Araçá}

Quando questionada sobre a importância da Baía do Araçá, a maioria dos entrevistados, independentemente da idade, afirmou haver algum tipo de importância (Figura 2a). Em relação a qual ou quais importâncias a Baía do Araçá tinha, foram diversas as respostas proferidas pelos entrevistados, até em depoimentos espontâneos (desvinculados da pergunta específica), sendo classificadas nas categorias: pesca, lazer, paisagística, processos ecológicos, cultural e sentimental (Figura 2b). Nem todas as categorias foram registradas em todas as classes etárias. Mas, quando registradas, as porcentagens variaram, evidenciando assim as diferentes formas de perceber a área. Importante salientar que ninguém negou a importância da baía.

De maneira geral, os indivíduos mais jovens (07 a 16 anos) indicaram o lazer (31\%), a pesca (25\%) e a importância ecológica $(25 \%)$ como os principais motivos.

É muito importante, tem muita gente que pesca aí. E por causa que dá pra brincar bastante, nadar, andar de barco. E também eu já vi uma baleia aqui (Estudante, 7 anos).

Para os entrevistados de 17 a 34 anos, foi constatada a predominância das categorias pesca $(43 \%)$, lazer (29\%) e cultura (21\%).

Eu pelo menos, como caiçara, eu acho que aquela praia (refere-se às praias da Baía do Araçá) é a parte da infância de muita gente e faz parte da nossa identidade cultural. Porque hoje em dia as crianças ainda vão pra lá, pra poder brincar (Estudante, 19 anos).

Ah, o Araçá é em frente de casa né. Tem bastante caiçara aqui que vive de lá ainda... Moro ali no alto e dá pra ver a praia. O pessoal vive catando berbigão lá, catando caranguejo, com a molecadinha (Controlador de praias, 32 anos).

Nesses trechos, podemos notar que, por mais que os indivíduos não usem a baía na atualidade, eles sabem de sua importância e têm conhecimento sobre a região. 
Em relação à classe entre 35 e 50 anos, a importância para a pesca (40\%) foi a mais relatada, seguida da ecológica (33\%). Foi citada ainda a importância sentimental (7\%). A pesca também foi abordada como principal importância da Baía do Araçá (53\%) para os indivíduos de mais idade (acima de 50 anos), mas as importâncias paisagística e ecológica também foram salientadas ( $20 \%$ cada).

Pra nós que pescamos tem muita importância. Porque ali nós temos criador de camarão, é o lugar aonde a gente pesca, entendeu? Então tudo isso dai, tem a importância que tem da natureza e também porque é bonito demais isso aqui (Pescador, 56 anos).

Houve também algumas falas levantando a questão do potencial educacional da Baía do Araçá, como, por exemplo:

É importante para os mais jovens. Eles precisam daquilo ali para estudo, pra ver como é que era no passado aquilo ali e a importância que tem até hoje (Fotógrafo, 63).

Ao invés de levar a criançada da escola, pro cinema eles podiam muito bem pegar um ônibus ai e ir no Araçá. Meu, a molecada ia ficar maravilhada, um monte de coisa, bicho morto, caranguejo, água viva... Pô, milhões de dúvidas que eles iam ter ali, iam tirar ali mesmo (Controlador de praias, 32 anos).

Os entrevistados que registraram que a Baía do Araçá tinha pouca importância $(n=3)$ ou não souberam responder $(\mathrm{n}=1)$ mostraram não conhecer muito bem a Baía ou não utilizá-la de nenhuma forma.

Ah, como eu não utilizo mar nem praia, não acho importante. Mas pra quem pesca e existe navegação de barco é muito importante mesmo (Dona de casa, 49 anos).

Quando questionada sobre a importância pessoal da Baía do Araçá, a maioria dos entrevistados, também independentemente da idade, afirmou haver tal importância (Figura 2c). As pessoas que afirmaram que a Baía do Araçá tinha pouca ou nenhuma importância pessoal (30\%) justificaram por não usar muito a baía ou não souberam explicar o motivo. Os motivos atribuídos à importância pessoal em relação à Baía do Araçá foram categorizados, de forma semelhante à apresentada para a questão anterior, em: pesca, lazer, paisagem, ecologia, cultura e sentimental (Figura 2d).

Para a menor classe etária (07 a 16 anos), foi levantada com maior frequência (40\%) a questão do lazer como principal importância pessoal. Mas a pesca $(20 \%)$ e a infância $(20 \%)$ também foram destacadas. "Infância" (categorizado como sentimental) foi o motivo mais abordado pelos indivíduos entre 17 e 34 anos de idade (57\%), seguido por "cultura" (29\%) e "pesca" (14\%). Essas três importâncias podem ser entendidas nesse curto trecho de entrevista:

Ah, a gente cresceu aqui né. Passei minha infância toda aqui e a gente pesca aqui também desde pequeno, igual nossos pais (Pescador e pizzaiolo, 19 anos).

Para a classe etária de 35 a 50 anos, a "cultura" e a importância sentimental ( $44 \%$ cada) dividiram o espaço entre os motivos mais levantados. Destaca-se, a título de ilustração, o seguinte trecho:

É o lugar onde eu vivi né, criei meus filhos. Então é a nossa raiz. A nossa raiz tá ali né, tá fincada ali 
(Pedreira, 50 anos).

Na classe maior que 50 anos houve uma distribuição homogênea entre as categorias, que ficaram entre: pesca, paisagem, cultura, sentimental e "não sabe".

Analisando essas informações ("importância" e "importância pessoal") como um todo (Figura 2), nota-se que, mesmo que o indivíduo não atribua uma importância pessoal à enseada, ele sabe de sua importância, o que é indicado pelo aumento na quantidade de respostas "não" ou "mais ou menos"

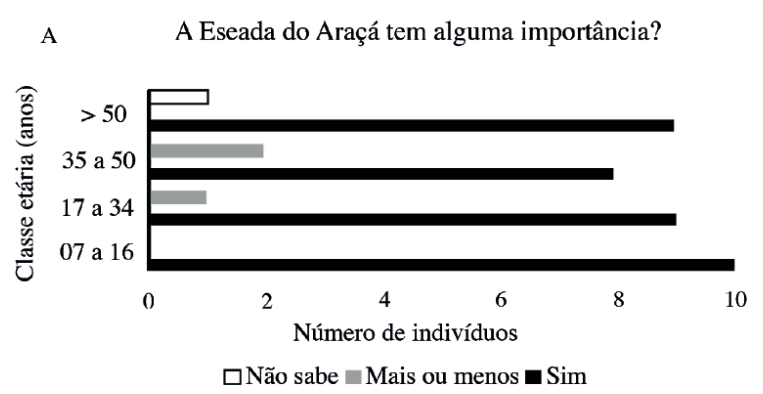

C A Eseada do Araçá é importante para você?

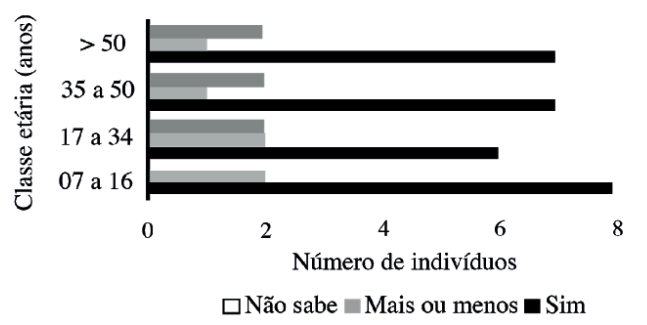

FIGURA 2 - Respostas dos entrevistados da Baía do Araçá quanto ao indicador “importância”: a) Atribuição de importância à Baía do Araçá; b) Tipo de importância geral; c) Atribuição de importância pessoal à Baía do Araçá; d) Tipo de importância pessoal. para a pergunta sobre importância individual (Figura $2 \mathrm{a}$ em relação à Figura 2c). No geral, as pessoas citaram a pesca e o lazer como as principais importâncias da Baía do Araçá (Figura 2b), mesmo que as importâncias pessoais sejam diferentes, sendo as mais citadas: sentimental e cultural (Figura 2d). Isso traz à tona um dado interessante: a relevância de se ter o conhecimento das importâncias e dos valores de um local, mesmo que não tenha um significado pessoal.

\subsection{Senso de pertencimento em relação à}

B Qual(is) importância(s)?
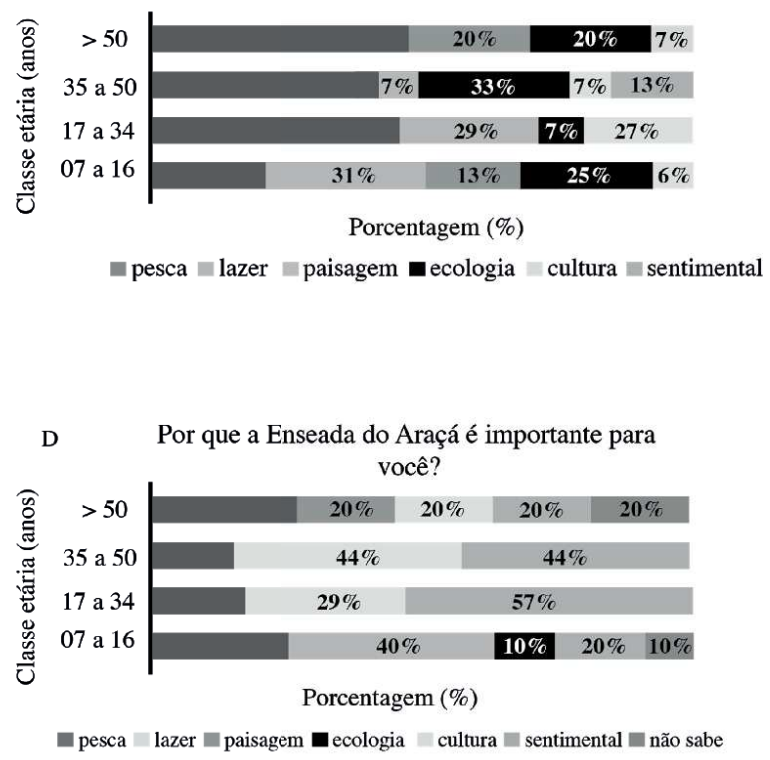


\section{Baía do Araçá}

Quando questionada se gostaria de morar em outro lugar, a maioria dos indivíduos, independentemente da idade, respondeu que não (Figura 3a). Dentre os motivos estavam: o costume, a beleza, a tranquilidade e o "gostar do lugar" (Figura 3b).

Para os indivíduos mais jovens, englobando as duas classes etárias, de 07 a 16 anos e de 17 a 34 anos, o motivo mais citado foi "gostar do lugar" (72\% e $66 \%$, respectivamente), seguido por "costume" ( $28 \%$ e $34 \%$, respectivamente). Na classe etária de 35 a 50 anos, a razão levantada com maior frequência foi "gostar do lugar" (76\%), seguido por "beleza" (24\%). "Tranquilidade" (50\%) e "gostar do lugar" $(50 \%)$ foram os dois motivos citados pelos entrevistados de maior classe etária (mais que 50 anos).

Onde vai ter lugar melhor que esse? Gosto muito daqui. Aqui é tranquilo, sossegado, aqui é um paraíso (Marinheiro e artesão de canoas, 54 anos).

Para aqueles que disseram talvez querer morar em outro lugar ( $\mathrm{n}=4$, um indivíduo em cada classe etária), não houve um padrão em relação aos motivos (estudos, crescimento exacerbado do local e motivos sentimentais).

Quando arguidos se usavam de alguma maneira a Baía do Araçá, a maioria dos entrevistados afirmou que usa ou já usou, independente da classe etária (Figura 3c). Apenas cinco indivíduos disseram não usar a Baía ( $\mathrm{n}=2$ para classe de 17 a 34 anos, $n=1$ para classe de 35 a 50 anos e $n=2$ para classe de 51 anos em diante) e todos argumentaram não usar por não gostar muito de praia ou não gostar de sair de casa.

Em relação ao tipo de uso, por meio dos discursos dos entrevistados, pôde-se identificar três categorias principais: pesca, trabalho e lazer (Figura 3d), notando-se claramente um padrão em relação aos tipos de uso da Baía do Araçá com a classe etária. Para os mais jovens, o uso se dá majoritariamente para o lazer (77\%), o que é de se esperar, já que são crianças. Na medida em que a classe etária vai aumentando, o uso para o lazer diminui, são feitas menções ao trabalho e o uso para pesca se mostra mais presente. Já na classe etária dos indivíduos de mais idade, a pesca aparece como o principal uso $(50 \%)$, seguida pelo trabalho (36\%) e, por último, lazer $(17 \%)$.

Optou-se aqui por separar a pesca de outros tipos de trabalho, para melhor análise de uma atividade tradicional das comunidades caiçaras. As atividades de trabalho assim categorizadas são: retiradas de matéria-prima para artesanato, uso para abrigo de embarcações, uso como ambiente de trabalho, como local de estudo do meio para professores e local de inspeção para controladores de praias.

Esses dados reforçam a atribuição de importância demonstrada anteriormente, onde os mais jovens entrevistados dão maior importância à Baía do Araçá pelo lazer e os mais velhos abordam mais a importância pela pesca.

Em relação à participação em atividades ou eventos relacionados à Baía do Araçá, apenas a classe etária de 17 a 34 anos mostrou-se pouco participativa, mas mesmo assim a maioria dos indivíduos ( $\mathrm{n}=8$ para classe de 07 a 16 anos, $\mathrm{n}=6$ para classe de 17 a $34, n=8$ para classe de 35 a 50 anos e $n=9$ para classe de 51 anos em diante), em todas as classes etárias, afirmou participar ou já ter 
participado (Figura 3e). Praticamente todos os entrevistados que afirmaram participação nos eventos citaram a regata de canoas como o principal.

Ah, eu vou lá assistir. Mas eu quero muito participar da regata, não aguento mais esperar. Ano que vem eu participo, porque é só pra quem tem mais de 8 anos (Estudante, 7 anos).

A Gostaria de morar em outro lugar?

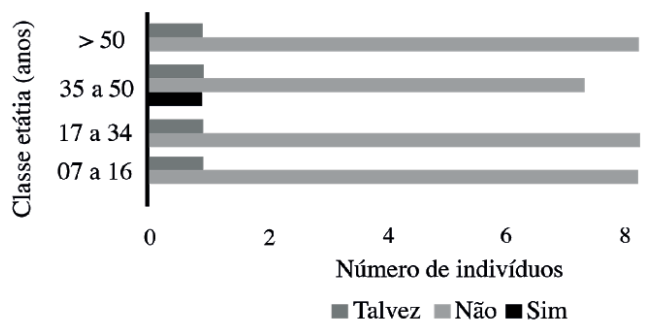

C Usa ou usava a Enseada do Araçá de alguma

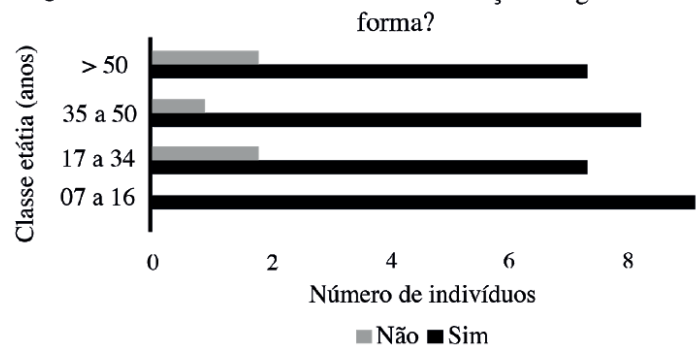

E Já participou de eventos relacionados à Enseada

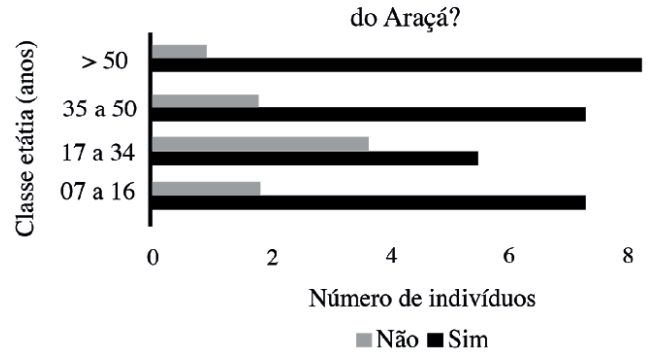

Ah, tem todo ano e eu participo sempre (Pescador, 71 anos).

Apenas dois indivíduos, da classe etária entre 07 e 16 anos, citaram mutirões de limpeza de praias, que são atividades realizadas semestralmente por algumas escolas da região.

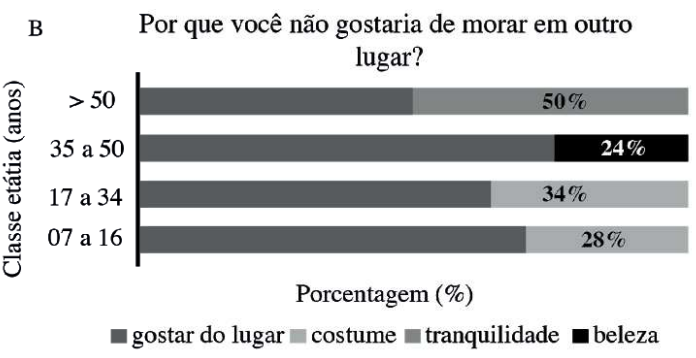

D Qual(is) forma(s) de uso?
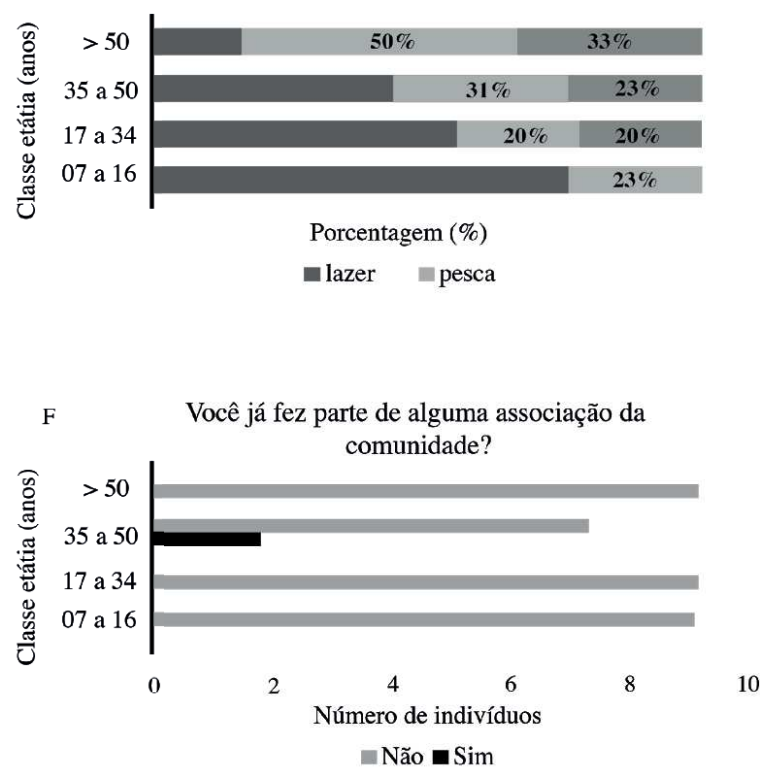

FIGURA 3 - Respostas dos entrevistados da Baía do Araçá quanto ao indicador "senso de pertencimento", por classe etária: a) Desejo de morar em outro lugar; b) Motivos atribuídos a não querer morar em outro lugar; c) Existência de uso pessoal da Baía do Araçá; d) Formas de uso da Baía do Araçá; e) Participação em atividades ou eventos relacionados à Baía do Araçá; f) Participação em associações da comunidade. 
Ao serem questionados sobre a participação em algum tipo de associação relacionada à Baía do Araçá, quase $100 \%$ dos entrevistados, independente da classe etária, disseram nunca ter participado. Apenas dois indivíduos, da classe etária de 34 a 50 anos, afirmaram ter feito parte de associação de bairro do Varadouro (Figura 3f).

Os mais jovens nunca terem participado pode se justificar pela pouca idade para participar de tais organizações. A falta de participação das demais classes etárias foi justificada pela não funcionalidade da associação de bairro do Varadouro, a única apontada, já que não há associação de pesca, artesãos ou alguma outra.

A gente tem que pôr na nossa cabeça uma coisa: a gente nunca pode contar, principalmente, com a prefeitura de São Sebastião, que eu já pedi muitas vezes pro presidente de bairro e Ave Maria! Já pedi limpeza, iluminação... E até hoje não recebi resposta (Vigilante, 58 anos).

\subsection{Senso de responsabilidade em relação à Baía do Araçá}

A maioria dos entrevistados, ao ser questionada sobre a existência de problemas em relação à Baía do Araçá, respondeu positivamente, independente da classe etária (Figura 4a). Os problemas foram classificados em categorias: esgoto, lixo, Porto de São Sebastião (operação atual e ampliação) e outros (drogas, Emissário Submarino do Araçá, Terminal Marítimo Almirante Barroso (TEBAR), vazamento de óleo, assoreamento e construção irregular). De maneira geral, a maioria dos entrevistados apontou o lixo (45\%) e o esgoto (40\%) como os principais problemas na Baía do Araçá (Figura 4b).

A maior parte dos entrevistados, também independentemente da classe etária, se mostrou incomodada com os problemas levantados em relação à Baía do Araçá (Figura 4c).

Ah, me incomoda bastante. Até caco de vidro tem lá, já me machuquei. E ali quando a maré sobe, traz os lixos todinhos né (Estudante, 19 anos).

Ah sim filha, eu me incomodo sim. Sabe por quê? Porque uma praia como essa daqui, não vou te dizer que é uma das melhores, mas a praia do Araçá, você conhece a praia do Araçá? Aquilo lá é um espetáculo. Pena que agora ela vai acabar. E também se fosse tudo limpinho, a baía aqui, dava pra você entrar, dava pra você tomar um banho, entendeu? (Dona de casa, 60 anos).

Sobre a responsabilidade pela solução dos problemas levantados em relação à Baía do Araçá, foram criados os seguintes agrupamentos, de acordo com os discursos dos entrevistados: moradores, população em geral, governo, Organizações Não Governamentais (ONGs) e "não sabe" (Figura 4d).

Para a menor classe etária desse estudo (07 a 15 anos), a maior parte das respostas responsabilizou os moradores (38\%), seguido de "governo" (23\%) e "população em geral" (23\%).

Acho que como a gente sabe que nem sempre a politica funciona como deveria, acho que os jovens podiam ajudar, podiam intermediar isso pra poder melhorar (Estudante, 15 anos).

Para os indivíduos de 17 a 34 anos, as categorias ficaram, no geral, bem distribuídas, com um pequeno destaque para "ONGs" e "não sabe" (27\% cada). Na classe etária de 35 a 50 anos, "população 
em geral" (44\%) e "governo" (44\%) foram as categorias que mais se destacaram.

Eu acho que teria que partir do governo Federal né, de lá de Brasília, depois do Estadual até chegar no Municipal. Teria que ter esses três aí, juntamente com a população, pra estar chegando num consenso né. Eu acho muito chato, machuca muito

A Você acha que há algum problema na Enseada do

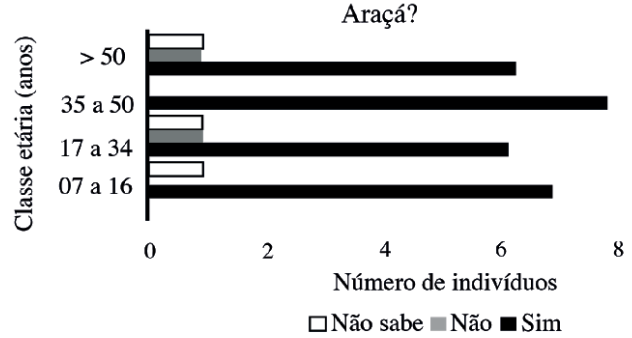

C Você se incomoda com esses problemas?

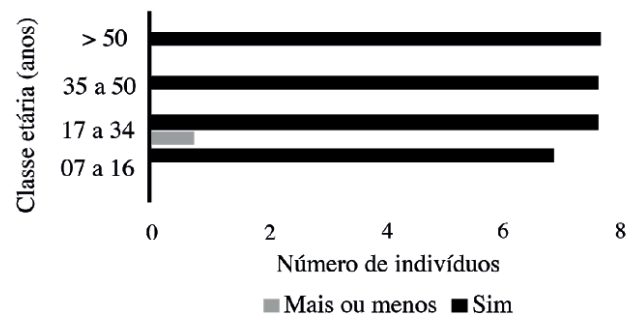

E Você acha que pode contribuir para a solução

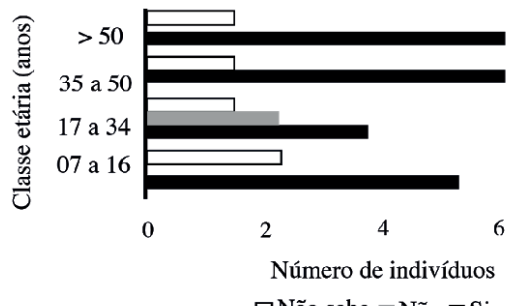

FIGURA 4 - Respostas dos entrevistados da Baía do Araçá quanto ao indicador "senso de responsabilidade", por classe etária: a) Existência de problemas na Baía do Araçá; b) Problemas citados pelos entrevistados; c) Incômodo com os problemas citados; d) Atribuição da responsabilidade pela solução dos problemas; e) Possibilidade de contribuir na solução dos problemas em relação à Baía do Araçá. a gente eles virem com uma ideia e pegar "ó, vai ser assim” " não chamar a gente pra um diálogo né (Pescador e professor de educação física, 42 anos).

Os entrevistados com mais de 50 anos de idade apontaram "governo" (60\%) como o principal responsável pela solução dos problemas na Baía do Araçá.

B Qual(is) o(s) problema(s)?

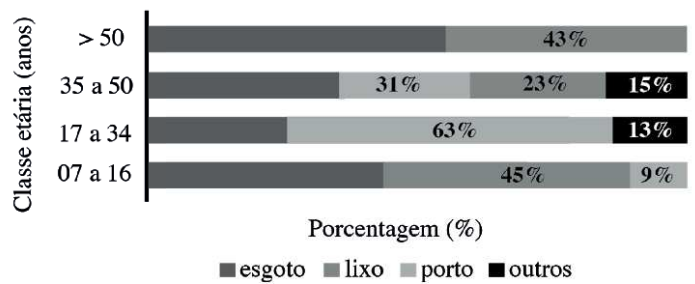

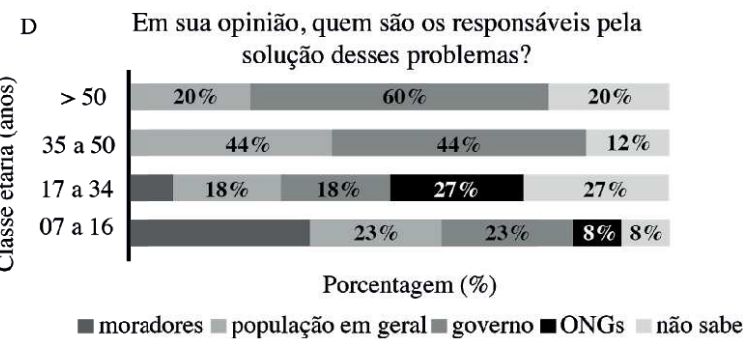


Ah, os nossos governantes não estão nem ai com a gente [...] Eles deveriam fazer um projeto bacana, de educação ambiental, com as crianças das escolas, sabe (Dona de casa, 51 anos).

Nesses relatos, é possível identificar a carência de políticas públicas eficientes que estimulem a participação da comunidade e a necessidade de ações que visem a uma política ambiental, com programas educativos. Esse quadro aponta uma falha no processo de comunicação para a gestão da região.

É interessante notar que os indivíduos mais novos atribuem a si mesmos mais responsabilidade, tanto pelo surgimento como pela solução dos problemas na Baía do Araçá, e os mais velhos tendem a terceirizar essa responsabilidade, expressando uma descrença no governo.

Quando perguntados diretamente se achavam que podiam contribuir para a solução dos problemas levantados, a maior parte respondeu de forma positiva. Apenas os entrevistados com classe etária entre 17 a 34 anos se mostraram menos dispostos. Para esse último grupo, três indivíduos disseram achar que não poderiam contribuir em nada e dois indivíduos disseram não saber (Figura 4e).

Aqueles que disseram achar que não poderiam contribuir em nada para a solução dos problemas justificaram não acreditar que fariam alguma diferença, como exemplifica o seguinte trecho:

Ah, eu acho que nessa altura não adianta mais. Porque tá chegando a ampliação do porto ali... E acho que não ia mudar mais (Estudante, 19 anos).

\subsection{Interesse por questões relacionadas à Baía do Araçá}

Em relação à participação em atividades visando à mudança ou à melhoria da Baía do Araçá (Figura 5a), os indivíduos acima de 50 anos mostraram-se mais participativos quando comparados aos demais. Porém, de maneira geral, com exceção da classe etária de 17 a 34 anos, houve predominância de respostas afirmativas.

A atividade mais citada pelos entrevistados foi a limpeza de praias, que ocorre anualmente na Baía do Araçá, seguida da Regata de Canoas e outras atividades desenvolvidas pelo Movimento Apaixonadas pelo Mangue, criado por moradores da região com o intuito de promover a preservação do manguezal do Araçá.

Quando questionados se havia interesse em participar de projetos futuros relacionados à preservação da Baía do Araçá, a maior parte dos entrevistados respondeu que sim, independentemente da idade, com destaque para a classe etária mais jovem, na qual todos demonstraram interesse (Figura 5b). Sugestões de maneiras mais interessantes e funcionais para esses projetos serem elaborados foram apontadas, como pode ser exemplificado no trecho a seguir:

Acho que devia ser uma coisa mais acessivel pra gente, acho que seria uma boa. Um projeto bem mais acessivel assim, e direto... Não que vá só ensinar na teoria, uma coisa que a gente vá agir. Um projeto nesse sentido seria muito legal (Estudante, 15 anos).

A maioria dos entrevistados, independente da classe etária, acredita que haverá algum tipo de influência na Baía do Araçá e região se o Porto de São Sebastião for ampliado (Figura 5c). É importante relatar que a questão da ampliação do Porto 
de São Sebastião foi abordada com frequência e espontaneamente pelos entrevistados logo no começo da conversa, independente da classe etária. Isso evidencia como esse assunto faz parte do cotidiano da comunidade estudada e que todos parecem saber, pelo menos um pouco, sobre o assunto.

Com relação ao tipo de influência possivelmente gerada pela ampliação do Porto, as respostas foram classificadas em: impactos positivos e impactos negativos (Figura 5d). A predominância de respostas ( $87 \%$ no geral) foi no sentido de apontar impactos negativos na Baía do Araçá e região, sem relação evidente com a classe etária dos entrevistados.

C Em sua opinião, se o Porto de São Sebastião for ampliado, a Enseada do Araçá e região serão influenciados?

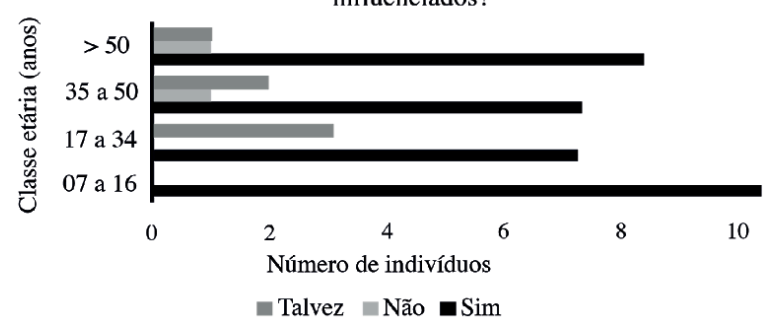

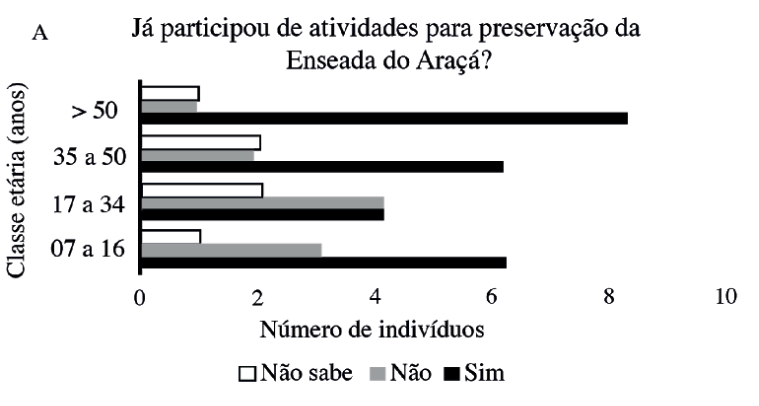

Nos trechos de entrevistas a seguir podem ser observados os principais tipos de influências, positivas ou negativas, apontadas:

Vai mudar muito, porque meu pai não vai mais poder sair pra pescar aqui e pegar siri. E também vai matar muita vida que tem aí, um montão de peixe (Estudante, 7 anos).

Acho que vai ser bom em certa parte, porque vai gerar mais empregos... Mas e aqueles que não sabem se sustentar além da pesca? Aí eu acho ruim (Estudante, 16 anos).

Eu acho que a Baía do Araçá vai sumir. Não vai aterrar, mas mesmo assim vai cobrir tudo... Os bichos precisam de luz né. Imagina? Vai acabar do mesmo jeito... Mas quem sou eu pra falar alguma

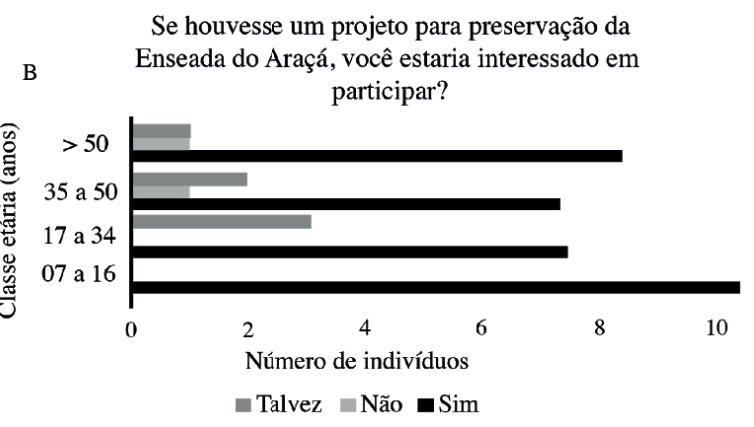

D Influências positivas ou negativas?

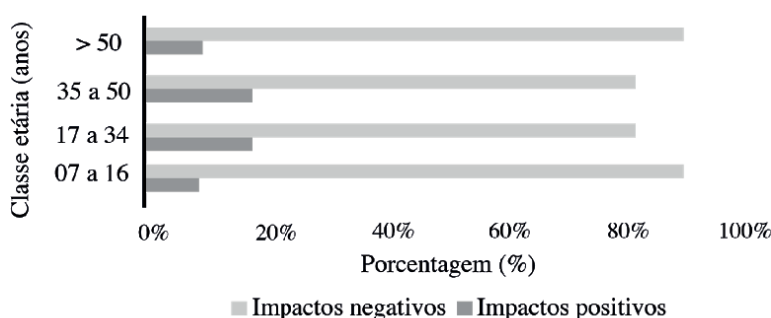

FIGURA 5 - Respostas dos entrevistados da Baía do Araçá quanto ao indicador “interesse”, por classe etária: a) Participação em atividades para preservação da Baía do Araçá; b) Interesse em participar de futuros projetos para preservação da Baía do Araçá; c) Existência de influência pela ampliação do Porto de São Sebastião; d) Tipos de influências possíveis pela ampliação do Porto de São Sebastião. 
coisa né? (Controlador de praias, 32 anos).

Ah, eu acho que vai mudar muito porque além da poluição ecológica tem a poluição sonora né, tem o trânsito, aumento da criminalidade e prostituição (Pescador e professor de educação física, 42 anos). Ah, que é benéfico é né. É progresso, é riqueza para o país e para o Estado. Pro município mais ou menos né. É muito enganoso isso aí. As pessoas pensam que vão ganhar muitos empregos aí, mas não é assim não. O pessoal que vai trabalhar aí e ter emprego bom mesmo vem tudo de fora. Tudo panelinha, tudo americano, japoneses... Daqui é a turma que vai varrer rua, sabe como é (Pescador, 71 anos).

De maneira geral, as influências positivas indicadas por poucos indivíduos são identificadas como geração de empregos e crescimento econômico para o Estado. Porém, é interessante notar que os discursos que apontam essas questões estão sempre acompanhados de um "mas": "vai ter mais empregos, mas vai ser ruim para os pescadores", "geração de empregos, mas só para o pessoal de fora", ou, ainda, "vai ser bom para o Estado, mas para o Município não".

A temática sobre a geração de empregos foi bastante citada, principalmente pelos indivíduos de mais idade e quase sempre com um viés negativo, pois apontam que para a população local os empregos serão ruins, de serviço braçal e com baixos salários. Foi identificada uma preocupação acentuada com a desapropriação das casas do bairro e a diminuição ou o impedimento da pesca tradicional local, levando a uma possível descaracterização cultural. Outros impactos também foram citados, como poluição ambiental, visual e sonora, aumento do tráfego, criminalidade e prostituição.
Com a análise das entrevistas, percebe-se que a maioria dos indivíduos entrevistados tem conhecimento sobre o projeto de ampliação do Porto e tem suas opiniões e argumentos formados quanto a isso. Nota-se também, em alguns discursos, o sentimento de impotência quanto à problemática da ampliação do Porto: os indivíduos não querem sua ampliação, mas acham que nada podem fazer para mudar.

\section{Discussão}

Apesar de os indivíduos mais jovens não apresentarem diferenças marcantes nas percepções ambientais quanto à importância, ao senso de pertencimento, à responsabilidade e ao interesse em relação à Baía do Araçá, notam-se algumas diferenças nos indicadores que se relacionam parcialmente com a idade. Mas nada que denote um distanciamento dos indivíduos mais jovens, moradores do bairro Varadouro, em relação à Baía do Araçá, como presumido inicialmente. Esse resultado vai ao encontro, portanto, do estudo de Trenouth et al. (2012), em que a idade também não influenciou, estatisticamente, a percepção ambiental dos indivíduos. No entanto, os autores ressalvam o fato de tal ausência de influência poder ser explicada pela desigualdade na representação das classes etárias na população de estudo. Já Van Liere \& Dunlap (1980) identificaram uma maior preocupação ambiental nos indivíduos mais jovens, enquanto para Shen \& Saijo (2008) o resultado foi o inverso. Todavia, os resultados do presente estudo são de difícil comparação com a literatura (Van Liere \& Dunlap, 1980; Shen \& Saijo, 2008; Villar et al., 2008), especialmente pelas diferenças metodológicas e de embasamento teórico. Em Van Liere \& Dunlap (1980) e em Shen 
\& Saijo (2008), foram realizados estudos restritos à concepção de "preocupação ambiental" e não à percepção ambiental. Já em Villar et al. (2008), os autores se referem à identificação de uma maior percepção ambiental pelos mais velhos.

No que diz respeito ao indicador "importância”, percebe-se uma diferença na atribuição de valores e de importâncias quanto às classes etárias, mas poucos padrões puderam ser identificados. Pode-se dizer que os entrevistados mais jovens se mostram ligados preferencialmente ao lazer que a baía proporciona e à pesca familiar. Para os mais velhos, a pesca predomina como tema de grande importância. No entanto, mesmo as pessoas que afirmaram que a Baía do Araçá tinha pouca ou nenhuma importância pessoal identificaram a importância para outras pessoas.

Essa diferença encontrada no que se refere à importância pessoal que o local tem para os indivíduos e o reconhecimento de uma importância geral para a comunidade mostra que ter o conhecimento dos valores locais pode fazer com que a pessoa se importe com a região. Isso indica que a desinformação muitas vezes leva a sociedade a uma postura de desresponsabilização. Há necessidade de incrementar o acesso à informação e a conteúdos educacionais, promovendo o crescimento da consciência ambiental como controle de degradação ambiental e motivador de inclusão social na gestão ambiental (Jacobi, 2003).

Para o indicador "senso de pertencimento", há uma diferença que depende parcialmente da classe etária, mas a maioria dos indivíduos entrevistados gosta de morar ali, usa a baía de diferentes formas e participa de algum evento local, demonstrando se sentir pertencente à região da Baía do Araçá. $\mathrm{O}$ uso sim tem uma forte relação com a idade, onde os mais jovens usufruem da Baía para o lazer e os mais velhos para o trabalho e para a pesca.

Quanto ao "senso de responsabilidade", pode-se notar que a maioria dos entrevistados sabe dos problemas da região e se sente responsável por eles. Apenas os indivíduos da classe etária de 17 a 34 anos parecem atribuir a si próprios menor responsabilidade, ao contrário da classe etária mais jovem, de 07 a 16 anos. Destaca-se também a tendência de os indivíduos de mais idade atribuírem a responsabilidade ao governo. No Plano Local de Desenvolvimento Sustentável do Araçá, a Universidade também foi reconhecida como importante para ajudar na implementação das diretrizes para solucionar os problemas identificados na Baía (Turra et al., 2016).

E em relação ao "interesse", também não houve padrão quanto à classe etária. Apenas a classe etária de 17 a 34 anos se mostrou pouco interessada em participar de projetos futuros para a preservação do Araçá. Mas, de maneira geral, os indivíduos mostraram-se interessados em questões relacionadas à Baía do Araçá, como a ampliação do Porto de São Sebastião, bem como para a participação em projetos relacionados à preservação da área. Portanto, cabe notar que, independentemente do tipo de uso ou de importância que o entrevistado atribuiu à baía (diferentes motivações), ele se sentia pertencente e responsável pela região e tinha interesse por questões relacionadas a ela. No entanto, poucos moradores da Baía do Araçá participaram da elaboração do PLDS do Araçá (Turra et al., 2016). Neste contexto, não se pode deixar de considerar que é possível haver uma falsa tendência no sentido de mostrar interesse em projetos de preservação, já que falar sobre o cuidado com o meio ambiente se tornou uma obrigação moral ou ética, mas que não 
necessariamente é praticada no dia a dia (Martinez, 2012) ou reconhecida como importante.

Considerando-se as entrevistas em sua totalidade, sem distinção por classes etárias, uma série de observações pode ser feita. As importâncias predominantes atribuídas pelos entrevistados à Baía do Araçá foram: pesca, ecológica, lazer e cultural. E os principais usos: lazer, seguido de pesca e traba1ho. Isso sugere a identificação de alguns serviços ecossistêmicos 1 locais, como "fornecimento de alimento", "benefícios ecológicos" (diversidade biológica, condições físicas, depuração de efluentes etc.), "lazer e recreação", "transporte" e "patrimônio e identidade cultural”. Algumas pesquisas também utilizam a percepção ambiental no estudo de serviços ecossistêmicos, tanto para auxiliar na identificação como para analisar as diferentes relações dos indivíduos com os serviços ecossistêmicos locais (Marczwski, 2006; Benitez-Capistros et al., 2014; Carrilho, 2016; Turra et al., 2016).

Parece haver um interesse geral por iniciativas que visem à preservação da Baía do Araçá e região, porém, há a necessidade de projetos estruturados de forma a envolver toda a comunidade, e que sejam eficazes (Fernandes et al., 2003; Villar et al., 2008; Abecasis et al., 2013).

Verificou-se a funcionalidade de sensibilização de eventos como a "Regata de Canoas" na Baía do Araçá, bastante citada entre os entrevistados, como uma atividade que engloba cultura e lazer, atraindo indivíduos de todas as classes etárias para conhecerem e usarem a Baía de alguma forma. Eventos como esse representam uma ação edificadora na união da comunidade em torno do resgate cultural e do sentimento de pertencimento ao local e da preservação do meio ambiente (Santos et al., no prelo).

Notou-se insatisfação em relação às Políticas Públicas incidentes na região. Os entrevistados, em geral, demonstraram um descontentamento, principalmente quanto à falta de consulta à comunidade. Foi constatada também a pouca participação da comunidade em grupos ou associações locais, que parece ser devido à carência de associações funcionais e representativas, como associação de bairro, de pesca ou de artesãos. Segundo Bosa (2009), o Litoral Norte de São Paulo necessita de um intenso processo de fortalecimento comunitário, considerando iniciativas que promovam a motivação e a capacitação. Sugere-se, portanto, que a formação de uma associação comunitária estruturada no bairro Varadouro, que fortaleça a relação com a baía, possa vir a ser um facilitador para discutir seus problemas. Estudos sobre as relações entre comunidade, meio ambiente e manejo de conflitos mostram que trabalhar em múltiplos níveis e tipos de organizações sociais é crucial para o sucesso da gestão ambiental e oferece a oportunidade de empoderamento da comunidade (Beierle \& Konisky, 2000; Haro et al., 2005; Turra et al., 2016), fortalecendo tal iniciativa.

O lixo e o esgoto foram identificados, pela comunidade estudada, como os principais problemas relacionados à Baía da Araçá, e as atribuições das responsabilidades como sendo da população em geral e do governo. De acordo com Gama et al. (2011) e Martinez (2012), analisando o senso de responsabilidade, a maioria dos entrevistados tem uma visão de que a responsabilidade deve ser compartilhada por todos e reconhece a educação

${ }^{1}$ Serviços Ecossistêmicos são considerados os benefícios diretos e indiretos obtidos pelo homem a partir do funcionamento dos ecossistemas (Andrade \& Romeiro, 2009). 
como meio de tomada de consciência e sensibilização. Essas informações, todas adquiridas por meio do uso da percepção ambiental como ferramenta metodológica, servem de subsídio no processo de gestão ambiental local (Martinez, 2012) e auxiliam na criação de mecanismos duradouros de mudança social e ecológica (Fischer, 2015).

A questão da ampliação do Porto foi recorrente nas conversas dos moradores da região de estudo e é usualmente problematizada como algo que irá gerar mais impactos negativos do que positivos para a baía e para a comunidade. Situação similar também foi constatada em Mani-Peres et al. (2016), que registraram a preocupação da comunidade local com a situação de ampliação do Porto de São Sebastião, a maioria dos habitantes contra o projeto.

Por meio da análise das entrevistas, foi constatado que indivíduos que não utilizam a baía de nenhuma forma ou não conhecem muito bem a região (apesar de morarem ali desde o nascimento) são geralmente aqueles que possuem uma tendência de demonstrar distanciamento em relação a ela, independentemente da idade. Assim, constata-se que o envolvimento com o local está muito mais relacionado com o conhecimento, o uso e a criação de uma identidade com a região do que com a idade e o local de moradia. Diferentes usos influenciam potencialmente o modo como os indivíduos percebem o meio ambiente (Jung et al., 2011).

Apesar de não ser objetivo desta pesquisa aprofundar o conhecimento a respeito dos shifting baselines, as entrevistas mostram evidências desse processo. Apesar das grandes transformações (Amaral et al., 2015; Mani-Peres et al., 2016), os entrevistados de diferentes faixas etárias reconhecem a importância da baía). Mas essa temática ainda necessita ser estudada para compreendermos a per- cepção da comunidade com as mudanças que vêm acontecendo ao longo do tempo. Embora a baseline esteja mudando, devido às grandes transformações que a Baía do Araçá vem sofrendo ao longo do tempo (Mani-Peres et al., 2016), os impactos ambientais incidentes não levaram os jovens a um distanciamento da área, de forma que o uso do ambiente e a discussão dos problemas locais promovem um referencial coletivo que integra as percepções de indivíduos de diferentes faixas etárias. Quando não há pontos de vista conflitantes sobre os principais valores ligados ao meio marinho entre as gerações, gênero ou nível educacional de uma dada comunidade, existe ali uma forte identidade cultural orientada para o mar (Abecasis et al., 2013).

\section{Conclusão}

A análise da percepção ambiental demonstrou que não está ocorrendo um desapego dos mais jovens entrevistados quanto à Baía do Araçá. Notam-se diferenças de percepção ambiental entre os indivíduos das diversas classes etárias, mas nada que denote tal desapego.

Um padrão entre os indivíduos que demonstraram maiores distanciamento e indiferença quanto à baía foi identificado e concluiu-se que o conhecimento (informativo ou vivenciado) e o uso são fatores mais significativos para a criação de um vínculo ou identidade com o local do que outros, como proximidade física e tempo de contato. E é essa identidade que leva o indivíduo a querer cuidar e preservar o local.

Como forma de contribuir com a gestão das unidades de conservação na região, devem ser considerados os principais serviços ecossistêmicos, 
usos e problemas associados à Baía do Araçá; a insatisfação quanto às políticas públicas locais e a contrariedade em relação à ampliação do Porto de São Sebastião.

\section{Agradecimentos}

Gostaríamos de agradecer à Fundação de Amparo à Pesquisa do Estado de São Paulo (FAPESP) pelo financiamento desta pesquisa por meio do Projeto Biota/FAPESP - Araçá (Processo n. 11/503175). Ao Centro de Biologia Marinha da USP e ao Laboratório de Manejo, Ecologia e Conservação Marinha do Instituto Oceanográfico da USP pelo apoio à realização desta pesquisa. Às Escolas de São Sebastião e a toda comunidade da região da Baía do Araçá, que sempre nos recebeu com muito carinho, e à Oceanógrafa Marina Santana, responsável pela elaboração do resumo em inglês e pela revisão do artigo.

\section{Referências}

Abecasis, R. C.; Schmidt, L.; Longnecker, N.; Clifton, J. Implications of community and stakeholder perceptions of the marine environment and its conservation for MPA management in a small Azorean island. Ocean \& Coastal Management, 84, 208-219, 2013. doi: 10.1016/j.ocecoaman.2013.08.009

ANA - Agencia Nacional de Águas. Programa IX, 2012. Disponível em <http://www.participa.br/articles/public/0017/9483/161_publicacao 16032012065259.pdf>. Acesso em: out. 2016.

Amaral, A. C. Z.; Migotto, A. E.; Turra, A.; Schaeffer-Novelly, Y. Araçá: biodiversidade, impactos e ameaças. Biota Neotropica, 10(1), 219-264, 2010.

Amaral, A. C. Z.; Turra, A.; Ciotti, A. M.; Wongtschowski,
C. L. D. B. R.; Schaeffer-Novelli, Y. (Orgs.). A vida na Baía do Araçá: diversidade e importância. 1. ed. São Paulo, SP: Lume, 2015.

Andrade, D. C.; Romeiro, A. R. Serviços ecossistêmicos e sua importância para o sistema econômico e o bem-estar humano. Texto para discussão. IE/Unicamp, n. 155, fev. 2009. Disponível em: < http://eco.ib.usp.br/labvert/Servicos_ecossistemicos_e_Sistema_Economico\%20.pdf>.

Bartolomé, M. M. Técnicas de investigación: la indagación cualitativa y sus usos más comunes en Investigación Social. In: Consejería de Educación y Cultura, Planificación, Organización y Evaluación de Proyectos Sociales, Escuela de Animación de la Comunidad de Madrid, 1997.

Baum, J. K.; Myers, R. A. Shifting baselines and the decline of pelagic sharks in the Gulf of Mexico. Ecology Letters, 7, 135-145, 2004. doi: 10.1111/j.1461-0248.2003.00564.x

Beierle, T. C.; Konisky, D. M. Values, conflict, and trust in participatory environmental planning. Journal of Policy Analysis and Management, 19(4), 587-602, 2000.

Benitez-Capistros, F.; Hugé, J.; Koedam, N. Environmental impacts on the Galapagos Islands: identification of interactions, perceptions and steps ahead. Ecological Indicators, 38, 113-123, 2014. doi: 10.1016/j.ecolind.2013.10.019

Berchez, F.; Ghilardi, N.; Robim, M. J.; Pedrini, A. G.; Hadel, V. F.; Fluckiger, G.; Simões, M.; Mazzaro, R.; Klausener, C.; Sanches, C.; Bespalec, P. Projeto trilha subaquática: sugestão de diretrizes para a criação de modelos de educação ambiental em unidades de conservação ligadas a ecossistemas marinhos. OLAM-Ciência e Tecnologia, 7(3), 181-209, 2007.

Bergmann, M. Análise da percepção ambiental da população ribeirinha do Rio Santo Cristo e de estudante. Porto Alegre, Dissertação (Mestrado em Ecologia) - UFRGS, 2007.

Boni, V.; Quaresma, S. J. Aprendendo a entrevistar: como fazer entrevistas em ciências sociais. Revista Eletrônica dos Pós-Graduandos em Sociologia Politica da UFSC, 2(1), 68-80, 2005.

Bosa, P. Análise da participação e atuação das associações de bairro no gerenciamento costeiro integrado: diagnóstico da participação social na malha territorial, Litoral Norte do 
Estado de São Paulo. São Paulo, Dissertação (Mestrado em Oceanografia Biológica) - USP, 2009.

Bourdieu, P. A miséria do mundo. Petrópolis: Vozes, 1999.

Bradley, J. C.; Waliczek, T. M.; Zajicek, J. M. Relationship between environmental knowledge and environmental attitude of high school students. The Journal of Environmental Education, 30(3), 17-21, 1999. doi: 10.1016/j. sbspro.2014.01.577

Campbell, L. M.; Gray, N. J.; Hazen, E. L.; Shackeroff, J. M. Beyond baselines: rethinking priorities for ocean conservation. Ecology and Society, 14(1), 14, 2009. Disponível em: <http://www.ecologyandsociety.org/vol14/iss1/art14/>.

Canright, C. Shifting baselines. California Coast \& Ocean, 22(3), 9-12, 2006.

Capelle, M. C. A.; Melo, M. C. O. L.; Gonçalves, C. A. Análise de conteúdo e análise de discurso nas ciências sociais. Organizações Rurais \& Agroindustriais, 5(1), 2003. Disponível em: $<$ http://revista.dae.ufla.br:index.php:ora:article:view:251:248>.

Carrilho, C. D. Identificação e valoração econômica e sociocultural dos serviços ecossistêmicos da Baia do Araçá, São Sebastião, SP, Brasil. São Paulo, Dissertação (Mestrado em Ciência Ambiental) - USP, 2016.

Champagne, P. Elargissement de l'espace social ET crise de l'identité paysanne. Cahiers d'Economie et Sociologie Rurales, (3), 73-89, 1986.

Cicin-Sain, B.; Knecht, R. W. Integrated coastal and ocean management: concepts and practices. Washington, D.C.: Island Press, 1998.

Dagnino, E. ¿Sociedade civil, participação e cidadania: de que estamos falando? In: Mato, D. (Ed.). Políticas de ciudadanía y sociedad civil en tiempos de globalización. Caracas: FACES, 2004. p. 95-110.

Delmas, M.; Toffel, M. W. Stakeholders and environmental management practices: an institutional framework. Business Strategy and the Environment, 13, 209-222, 2004. doi: 10.1002/bse.409

Duarte, C. M.; Conley, D. J.; Carstensen, J.; Sánchez-Camacho, M. Return to Neverland: Shifting Baselines Affect
Eutrophication Restoration Targets. Estuaries and Coasts, 32, 29-36, 2009. doi: 10.1007/s12237-008-9111-2

Ehler, C. N. Indicators to measure governance performance in integrated coastal management. Ocean \& Coastal Management, 46, 335-345, 2003. doi: 10.1016/S09645691(03)00020-6

Fernandes, R. S.; Souza, V. J.; Fernandes, S. T. Uso da percepção ambiental como instrumento de gestão em aplicações ligadas às áreas educacional, social e ambiental. In: Anais do II Encontro da ENANPPAS. Indaiatuba, 26 a 29 de maio, 2003.

Ferrante, V. L. S. B.; Aly Junior, O. Assentamentos rurais: impasses e dilemas (uma trajetória de 20 anos). São Paulo: Incra/Uniara, 2005. p. 321- 349.

Fischer, A. P. A boundary-spanning organization for transdisciplinary science on land stewardship: The Stewardship Network. Ecology and Society, 20(4), 38, 2015. doi: 10.5751/ES-08121-200438

Fiorin, J. L. Elementos de análise do discurso. São Paulo: Contexto, 2000.

Gama, M. A.; Nascimento, D. E. S.; Ribeiro, C. L.; Ribeiro, R. F.; Fazolato, C. P.; Santana-Neto, S. P.; Silva, I. R. Percepção dos usuários sobre lixo costeiro na praia de Itapoã, Salvador, Bahia. In: Anais do XIV Congresso Latino-Americano de Ciências do Mar - XIV COLACMAR. Balneário Camboriú, 30 de outubro, 2011.

GESAMP - IMO/FAO/UNESCO-IOC/WMO/WHO/IAEA/ UN/UNEP Joint Group of Experts on the Scientific Aspects of Marine Environmental Protection. The contributions of science to coastal zone management, 1996. Disponível em: <http://www.fao.org/3/contents/dc824e26-b1b7-568d-8770-1f9347ecb063/W1639E00.HTM>.

Gohn, M. G. Educação não formal, participação da sociedade civil e estruturas colegiadas nas escolas. Ensaio: Avaliação e Políticas Públicas em Educação, 14(50), 27-38, 2006. Disponível em: <http://www.scielo.br/pdf/ensaio/ v14n50/30405.pdf>.

Halpern, B. S.; Walbridge, S.; Selkoe, K. A.; Kappel, C. V.; Micheli, F.; D’Agrossa, D.; Bruno, J. F.; Casey, K. S.; Ebert, C.; Fox, H. E.; Fujita, R.; Heinemann, D.; Lenihan, 
H. S.; Madin, E. M. P.; Perry, M. T.; Selig, E. R.; Spalding, M.; Steneck, R.; Watson, R. A global map of human impact on marine ecosystems. Science, 319(5865), 948-952. 2008.

Halpern, B. S.; Longo, C.; Hardy, D.; Mcleod, K. L.; Samhouri, J. F.; Katona, S. K.; Kleisner, K.; Lester, S. E.; O'leary, J.; Ranelletti, M.; Rosenberg, A. A.; Scarborough, C.; Selig, E. R.; Best, B. D.; Brumbaugh, D. R.; Chapin, F. S.; Crowder, L. B.; Daly, K. L.; Doney, S. C.; Elfes, C.; Fogarty, M. J.; Gaines, S. D.; Jacobsen, K. I.; Karrer, L. B.; Leslie, H. M.; Neeley, E.; Pauly, D.; Polasky, S.; Ris, B.; St Martin, K.; Stone, G. S.; Sumaila, U. R.; Zeller, D. An index to assess the health and benefits of the global ocean. Nature, 488, 615-620, 2012.

Haro, G. O.; Doyo, G. J.; Mcpeak, J. G. Linkages between community, environmental, and conflict management: experiences from northern Kenya. World Development, 33(2), 285-299, 2005. doi: 10.1016/j.worlddev.2004.07.014

Jacobi, P. R. Educação ambiental, cidadania e sustentabilidade. Cadernos de Pesquisa, 118(3), 189-205, 2003. Disponível em: <http://www.scielo.br/pdf/\%0D/cp/ n118/16834.pdf $>$.

Jacobi, P. R.; Barbi, F. Democracia e participação na gestão dos recursos hídricos no Brasil. Revista Katál, 10(2), 237 244, 2007. Disponível em: <http://www.scielo.br:pdf:rk:v10n2:a12v10n2.pdf $>$.

Jung, C. A.; Dwyer, P. D.; Minnegal, M.; Swearer, S. E. Perceptions of environmental change over more than six decades in two groups of people interacting with the environment of Port Phillip Bay, Australia. Ocean \& Coastal Management, 54, 93-99, 2011. doi: 10.1016/j. ocecoaman.2010.10.035

Kahn, P. H.; Friedman, B. Environmental views and values of children in an inner-city black community. Child Development, 66, 1403-1417, 1995.

Knopki, P. B.; Bollmann, H. A.; Brandalize, M. C. B. Avaliação da percepção ambiental dos moradores da Bacia hidrográfica do rio Belém - indicadores de contato, importância e participação. In: Anais do II Simpósio Brasileiro de Ciências Geodésicas e Tecnologias da Geoinformação. Recife, 09 de setembro, 2008.

Knowlton, N.; Jackson, J. B. C. Shifting baselines, local impacts, and global change on coral reefs. Plos Biology, 6(2), 54, 2008. doi: 10.1371/journal.pbio.0060054

Leite, G. C. O mestre navegante: o passado, o presente e o futuro do pescador artesanal. São José dos Campos: Papercrom, 2001.

Malafaia, G.; Rodrigues, A. S. L. Percepção ambiental de jovens e adultos de uma escola municipal de ensino fundamental. Revista Brasileira de Biociencias, 7(3), 266274, 2009.

Mani-Peres, C.; Xavier, L. Y.; Santos, C. R.; Turra, A. Stakeholders perceptions of local environmental changes as a tool for impact assessment in coastal zones. Ocean \& Coastal Management, 119, 135-145, 2016. doi: 10.1016/j. ocecoaman.2015.10.005

Marczwski, M. Avaliação da percepção ambiental em uma população de estudantes do ensino fundamental de uma escola municipal rural: um estudo de caso. Porto Alegre, Dissertação (Mestrado em Ecologia) - UFRGS, 2006.

Marques, D. V.; Colesanti, M. T. M. Uma proposta de educação ambiental para áreas verdes: o exemplo do bosque John Kennedy, Araguari, MG. In: Anais del Encuentro de Geografos de America Latina. Santiago, 05 de março, 2001.

Martinez, D. I. Representações e percepções sobre ambiente e conservação como subsídio ao Gerenciamento Costeiro Integrado: estudo de caso com grupos sociais da região de Cananéia, litoral sul do Estado de São Paulo. São Paulo, Dissertação (Mestrado Oceanografia Biológica) - USP, 2012.

Prado, L. R. T. Pescadores de Caraguatatuba: histórias e estórias. São Paulo: FUNDACC, 2001.

Oliveira, K. A.; Corona, H. M. P. Percepção ambiental como ferramenta de Propostas educativas e de políticas ambientais. Revista Cientifica ANAP Brasil, 1(1), 53-72, 2008.

Oliveira, N. R. Percepção ambiental como subsídio para gestão costeira: um estudo de caso na Enseada do Araçá, Litoral Norte do Estado de São Paulo. São Paulo, Monografia (Conclusão de curso de Graduação) - USP, 2013.

Pauly, D. Anecdotes and the shifting baseline syndrome of fisheries. Trends in Ecology \& Evolution 10, 430, 1995.

Papworth, S. K.; Rist, J.; Coad, L.; Milner-Gulland, E. J. 
Evidence for shifting baseline syndrome in conservation. Conservation Letters, 2, 93-100, 2009. doi:10.1111/j. 1755-263X.2009.00049.x

Pedrini, A. G.; Messas, T. P.; Pereira, E. S.; Ghilardi-Lopes, N. P.; Berchez, F. A. Educação ambiental pelo ecoturismo numa trilha marinha no Parque Estadual da Ilha Anchieta, Ubatuba (SP). Revista Brasileira de Ecoturismo, 3(3), 428-459, 2010.

Pedrini, A. G.; Bochniak, M. Percepção ambiental dos usuários da praia de Copacabana, cidade do Rio de Janeiro (RJ) sobre a problemática de resíduos sólidos. In: Anais do III Encontro Nacional de Educação Ambiental e V Encontro Nordestino de Biogeografia. João Pessoa, 12 de abril, 2013.

Pereira, C. C.; Silva, F. K.; Ricken, I.; Marcomin, F. E. Percepção e sensibilização ambiental como instrumentos à educação ambiental. Revista Eletrônica do Mestrado em Educação Ambiental, 20(2), 86-106, 2013.

Peterson, N. D. Excluding to include: No participation in Mexican natural resource management. Agriculture and Human Values, 28, 99-107, 2011. doi: 10.1007/s10460010-9258-X>.

Santos, C. R.; Xavier, L. Y.; Peres, C. M.; Stori, S. T.; Grilli, N.; Shinoda, D. C.; Santana, M.; Andrade, M. M.; Arantes, C. R. R.; Corrêa, M. R.; Vivacqua, M.; Serafini, T. Z.; Jacobi, P. R.; Seixas, C. S.; Turra, A. Prática da gestão costeira integrada: da mobilização à elaboração participativa de um Plano Local de Desenvolvimento Sustentável. In: Amaral, A. C. Z.; Turra, A.; Ciotti, A. M.; Rossi-Wongtschowski, C. L. D. B.; Schaeffer-Novelli, Y. (Orgs.). Subsídios para estudos da biodiversidade e funcionamento de ecossistemas costeiros. No prelo.

Shen, J.; Saijo, T. Reexamining the relations between socio-demographic characteristics and individual environmental concern: Evidence from Shanghai data. Journal of Environmental Psychology, 28(1), 42-50, 2008. doi: 10.1016/j. jenvp.2007.10.003

Shirazawa-Freitas, J. S. Gestão da zona costeira: políticas públicas e atores sociais na praia da Cocanha, Caraguatatuba, São Paulo. São Paulo, Dissertação (Mestrado em Oceanografia Biológica) - USP, 2012.

Steel, B. S.; Smith, C.; Opsommer, L.; Curiel, S.; Warner-S- teel, R. Public ocean literacy in the United States. Ocean \& Coastal Management, 48(2), 97-114, 2005. doi: 10.1016/j. ocecoaman.2005.01.002

Trenouth, A. L.; Harte, C.; Heer, C. P.; Dewan, K.; Grage, A.; Primo, C.; Campbell, M. L. Public perception of marine and coastal protected areas in Tasmania, Australia: importance, management and hazards. Ocean \& Coastal Management, 67, 19-29, 2012. doi: 10.1016/j.ocecoaman.2012.04.007

Turner, R. K. Integrating natural and socio-economic science in coastal management. Journal of Marine Systems, 25, 447-460, 2000. doi: 10.1016/S0924-7963(00)00033-6

Turra, A.; Santos, C. R.; Peres, C. M.; Seixas, S. C.; Shinoda, D. C.; Stori, F. T.; Xavier, L. Y.; Andrade, M. M.; Santana, M. F. M.; Rodrigues, M. V.; Grilli, N. M.; Jacobi, P. R.; Serafini, T. Z. (Orgs.). Plano Local de Desenvolvimento Sustentável da Baía do Araçá. São Paulo: Instituto Oceanográfico da Universidade de São Paulo, 2016.

Turvey, S. T.; Barrett, L. A.; Yujiang, H.; Lei, Z.; Xinqiao, Z.; Xianyan, W.; Yadong, H.; Kaiya, Z.; Hart, T.; Ding, W. Rapidly Shifting Baselines in Yangtze Fishing Communities and Local Memory of Extinct Species. Conservation Biology, 24(3), 778-787, 2010. doi: 10.1111/j. 1523-1739.2009.01395.x

UNESCO - United Nations Educational, Scientific and Cultural Organization. Expert Panel on Project 13: Perception of Environmental Quality, 1973. Disponível em: <http:// unesdoc.unesco.org/images/0000/000059/005984EB.pdf>. Acesso em: 20 out. 2013.

Van Liere, K. D.; Dunlap, R. E. The social bases of environmental concern: A review of hypotheses, explanations and empirical evidence. The Public Opinion Quarterly, 44, 181-197, 1980. doi: 10.1086/268583

Villar, L. M.; Almeida, A. J.; Lima, M. C. A.; Almeida, J. L. V.; Souza, L. F. B.; Paula, V. S. A percepção ambiental entre os habitantes da região noroeste do Estado do Rio de Janeiro. Escola Anna Nery Revista de Enfermagem, 12(3), 537-543, 2008. Disponível em: <http://www.scielo.br/pdf/ ean/v12n2/v12n2a13.pdf $>$.

Whyte, A. V. T. Guidelines for field studies in environmental perception. Paris: UNESCO, 1977. 
Wright, R.; Stein, M. Snowball sampling. In: Kempf-Leonard, K. (Org.). Encyclopedia of Social Measurement. San Diego: Elsevier, 495-500, 2005.
Xavier, L. Y. Participação de comunidades de pescadores tradicionais na implementação do Zoneamento Ecológico-Econômico Marinho e suas implicações: um estudo de caso no Litoral Norte de São Paulo. São Paulo, Dissertação (Mestrado em Oceanografia Biológica) - USP, 2010. 